\title{
CONCERNING THE EXISTENCE OF FRACTIONS OF THE SERICIN IN RAW SILK
}

\author{
By Henry A. Rutherford and Milton Harris ${ }^{1}$
}

\section{ABSTRACT}

The question of the possible existence of several fractions of the sericin of raw silk has been investigated. The relative yields of sericins $A$ and $B$, obtained after treatment of silk in an autoclave, were found to be dependent on the duration of the treatment. Practically all of the sericin removed in the early stages of autoclaving was in the form generally designated as sericin $B$. On continuing the treatment, this fraction was rapidly converted into the more soluble form, sericin A. Analyses of the fractions obtained after autoclaving the silk for different lengths of time showed that the alleged sericins $A$ and $B$ are not definite chemical entities, but are substances whose chemical compositions vary with the duration of the autoclave treatment. The results of the investigation show that the sericin fractions are artifacts, which result from the hydrolytic decomposition of the naturally occurring sericin during its removal from the fiber.

\section{CONTENTS}

I. Introduction

II. Experimental procedure

1. Materials and methods

2. Preparation of sericin solutions _._.

3. Fractionation of the sericin

4. Designation of the sericin fractions _. _ . .

III. Results and discussion

IV. References

\section{INTRODUCTION}

Raw silk fibers consist of at least two proteins, silk fibroin and silk sericin. The latter forms a coating over the fibroin and constitutes 15 to 30 percent of the total weight of the raw fiber. Removal of sericin from fibroin is based on the solubility of the former in hot aqueous solutions. The solubility increases considerably in the more alkaline or acid solutions.

A variety of concepts relative to the nature of sericin and the fractions obtained from it have appeared in the literature. In 1784 one of the first published records on the removal of sericin from silk by the use of alkaline solutions appeared $[1]^{2}$. A number of similar investigations followed until Cramer [2], in 1865, expanded the scope of the investigations and obtained several proteins by fractionation of

\footnotetext{
1 Research Associates at the National Bureau of Standards, representing the Textile Foundation, Inc.
}

2 Numbers in brackets indicate literature references at the end of this paper. $218089-40-4$ 
a solution of sericin. He suggested that these fractions were decomposition products of the naturally occurring material. Following his findings, Wetzel [3], Bondi [4], Fischer and Skita [5], and Anderlini [6], studied the removal of sericin from silk and concluded that sericin in raw silk exists in more than one modification, although good experimental evidence to substantiate such a conclusion was lacking. In the above-mentioned investigations, different procedures for the preparation of the sericin solutions were employed, and little analytical work was done to characterize the protein fractions which were obtained. As a consequence, widely different results were reported by the different investigators. For example, Bondi found two fractions in a solution of sericin obtained by boiling silk in water, while Anderlini was able to separate three fractions after a prolonged extraction of raw silk with water at $50^{\circ}$ to $60^{\circ} \mathrm{C}$.

More recently, Shelton and Johnson [7] isolated two fractions from sericin solutions which had been obtained by autoclaving raw silk in water at temperatures of about $115^{\circ} \mathrm{C}$. They concluded that raw silk sericin contains at least two proteins, one of which is soluble and the other insoluble in cold water. Subsequent investigators, using the autoclave to remove the sericin, appeared to substantiate these findings, and also attempted to define the properties of the isolated fractions. Mosher [8] stated that both fractions are very much alike chemically but possess different physical properties, especially with respect to solubility. He further noted that the insoluble fraction was converted into a soluble one by boiling in aqueous solution, the conversion being greatly accelerated by increasing the acidity, alkalinity, or temperature of the solutions. Although he concluded that sericin is composed of three distinct fractions, his results could be interpreted to mean that sericin does not exist as a mixture of proteins in raw silk, and that these fractions are decomposition products formed during the process of removal of the sericin from the fibers.

In contrast to some of the conclusions of Mosher, Kaneko [9], and Ito and Komori [10] found the different sericin fractions to be different chemically. Their results were based on determinations of the nitrogen distribution and the tyrosine contents of the isolated fractions. However, disagreements are found even between the data of these investigators. For example, Kaneko found that the soluble fraction is especially rich in arginine nitrogen, whereas Ito and Komori found a greater proportion of this nitrogen in the insoluble portion.

From consideration of the previous investigations, it became evident that no satisfactory conclusion concerning the existence of several fractions of the sericin of raw silk could be reached. In the present investigation an attempt was made to throw further light on the question by making a more extensive study of sericin and of the fractions obtained from it.

\section{EXPERIMENTAL PROCEDURE}

\section{MATERIALS AND METHODS}

Samples of white Japanese silk which had received no previous treatment other than that used in the reeling process were used in this work. The naturally occurring waxes were removed by cold extractions for 24 hours each with alcohol and ether. Analyses of the dewaxed fiber gave the values shown in table 1 . The data for sericin 
were calculated from the analytical data for the dewaxed silk and fibroin and from the determined sericin content.

Total nitrogen was determined by the microKjeldahl method, and tyrosine by Lugg's method [11], after an alkaline hydrolysis. The amino-nitrogen content of the fibrous and of the insoluble proteins was determined by the method of Rutherford, Harris, and Smith [12]. The method of Van Slyke [13] was used for the determination of the amino-nitrogen content of sericin solutions. Carbohydrate and amino sugars were estimated by the methods outlined by Sørensen $[14,15]$.

TABLE 1.-Total and amino-nitrogen, tyrosine, carbohydrate, and amino-sugar contents of the dewaxed silk, fibroin and sericin used in the present investigation

The data for sericin were calculated from the analytical data on dewaxed silk and fibroin and from the determined sericin content.

\begin{tabular}{|c|c|c|c|c|c|c|}
\hline Material & $\begin{array}{c}\text { Total } \\
\text { nitrogen }\end{array}$ & $\begin{array}{c}\text { Amino } \\
\text { nitrogen }\end{array}$ & Tyrosine & $\begin{array}{c}\text { Carbohydrate } \\
\text { (as glucose) }\end{array}$ & $\begin{array}{c}\text { Amino sugars } \\
\text { (as glucos- } \\
\text { amine) }\end{array}$ & $\begin{array}{l}\text { Sericin } \\
\text { content }\end{array}$ \\
\hline $\begin{array}{l}\text { Dewaxed silk } \\
\text { Fibroin } \\
\text { Sericin }\end{array}$ & $\begin{array}{l}\% \\
18.29 \\
18.73 \\
16.92\end{array}$ & $\begin{array}{r}\% \\
0.14 \\
.09 \\
.30\end{array}$ & $\begin{array}{r}\% \\
10.9 \\
12.3 \\
6.3\end{array}$ & $\begin{array}{c}\% \\
0.67 \\
.56 \\
1.0\end{array}$ & $\begin{array}{c}\% \\
0.80 \\
.30 \\
2.4\end{array}$ & ${ }^{\%} 23.7$ \\
\hline
\end{tabular}

a Determined by method of Rutherford, Harris, and Smith [12].

\section{PREPARATION OF SERICIN SOLUTIONS}

Most of the sericin solutions used in this work were prepared by an autoclaving method similar to that described by other investigators $[7,8,10]$. The raw silk was placed in a beaker of water at about $100^{\circ} \mathrm{C}$ in the autoclave, the ratio of fiber to water being 1 to 50 . Steam was passed into the autoclave until a temperature of $114^{\circ}$ to $115^{\circ} \mathrm{C}$ was reached. Approximately 5 minutes was required for this operation. The temperature was then maintained by addition of more steam for the duration of the treatment. The silk was removed from the solution, squeezed, and immediately rinsed in one $500-\mathrm{ml}$ portion of water at $90^{\circ} \mathrm{C}$. As much liquid as possible was squeezed from the silk and combined with the rinse solution and the solution obtained after autoclaving. The combined solutions were then rapidly cooled to room temperature in a water bath.

\section{FRACTIONATION OF THE SERICIN}

In earlier work, the fractionation of the sericin in solution was accomplished by the use of alcohol or ammonium sulfate, but in more recent work, most investigators have preferred to use different buffer solutions. It was found necessary, however, to redetermine the $\mathrm{pH}$ for maximum precipitation as the values reported in the literature $[8,10]$ vary from $\mathrm{pH} 3.6$ to 4.1. A preliminary experiment was made on a solution of sericin, prepared by a 30-minute treatment in the autoclave. The solution was brought to room temperature and aliquots of it were immediately adjusted to definite $\mathrm{pH}$ values in the range from 3.5 to 4.3 with acetate buffers of constant ionic strength $(0.02 M)$. After 15 hours, the precipitated protein was centrifuged off, and the total nitrogen content (a measure of the protein remaining in solution) and the $\mathrm{pH}$ of the supernatant liquid were determined. 
A considerable portion of the protein was precipitated in the $\mathrm{pH}$ range used, but maximum precipitation appeared to occur at $\mathrm{pH} 4.0$. In all subsequent fractionation experiments, the solutions were adjusted to this $\mathrm{pH}$ and allowed to remain in a refrigerator overnight before removal of the insoluble protein.

The fraction which is insoluble at $\mathrm{pH} 4$ was separated from the remainder of the solution with a centrifuge. The precipitate was thoroughly washed with fresh portions of the acetate buffer, then with alcohol and with ether, and finally dried for 4 hours in a vacuum oven at $50^{\circ} \mathrm{C}$.

The acetate washings were added to the solution remaining after centrifuging, and the whole was evaporated to a small volume by passing a stream of air over it at room temperature. The protein in the concentrate was precipitated by addition of the solution to a sufficient volume of alcohol (95 percent) at about $0^{\circ} \mathrm{C}$, to make the final concentration of alcohol 75 percent. The precipitate was separated from the solution with a centrifuge, washed with alcohol and with ether, and dried in the vacuum oven for 4 hours at $50^{\circ} \mathrm{C}$.

The solution remaining after the separation of the protein which was insoluble in 75-percent alcohol was combined with the alcohol and ether washings from both sericin fractions, evaporated to dryness on the steam bath, and the weight of the residue determined. The solid material was dissolved in a small amount of water, the solution diluted to $25 \mathrm{ml}$, and suitable aliquots were taken for nitrogen, tyrosine, and carbohydrate determinations.

\section{DESIGNATION OF THE SERICIN FRACTIONS}

The authors do not intend to perpetuate, in future papers, the use of the following terms for the designations of the sericin fractions. These terms, which were adopted by previous investigators, are used in this paper merely for convenience and to avoid further confusion. Sericin $B$ is the fraction of the protein which is insoluble at $\mathrm{pH} 4$. The fraction which is soluble at $\mathrm{pH} 4$ but insoluble in a 75 -percent solution of alcohol is called sericin $A$. In the present investigation, a small fraction soluble in a 75-percent solution of alcohol was also found. For convenience, this material is referred to as sericin $D$, although in a series arranged in descending order with regard to solubility, it should precede sericin $A$. The existence of another fraction, sericin $C$, has been reported and described by Mosher [8] as extremely insoluble.

\section{RESULTS AND DISCUSSION}

The effects on dewaxed silk of varying the duration of the autoclave treatment are shown in table 2 and figure 1 . About 80 percent of the total sericin of the sillk is removed in as little time as 20 minutes; practically complete removal is accomplished in approximately 1 hour. The yields of sericins $A$ and $B$ are seen to vary considerably with the duration of autoclaving. Of the total sericin removed during treatment of dewaxed silk for 5 minutes, more than 97 percent was in the form of sericin $B$. The yield of this fraction decreased, however, as the duration of the autoclave treatment was increased until, after 3 hours, only 18.7 percent of the total sericin was recovered in this 
form. On the other hand, the very low yield of 2.7 percent of sericin $A$, obtained during the 5-minute treatment, was increased to 77.4 percent by 3 hours in the autoclave. Only a small amount of sericin $D$ was present. As is shown in the last column, practically all of the sericin in solution was accounted for.

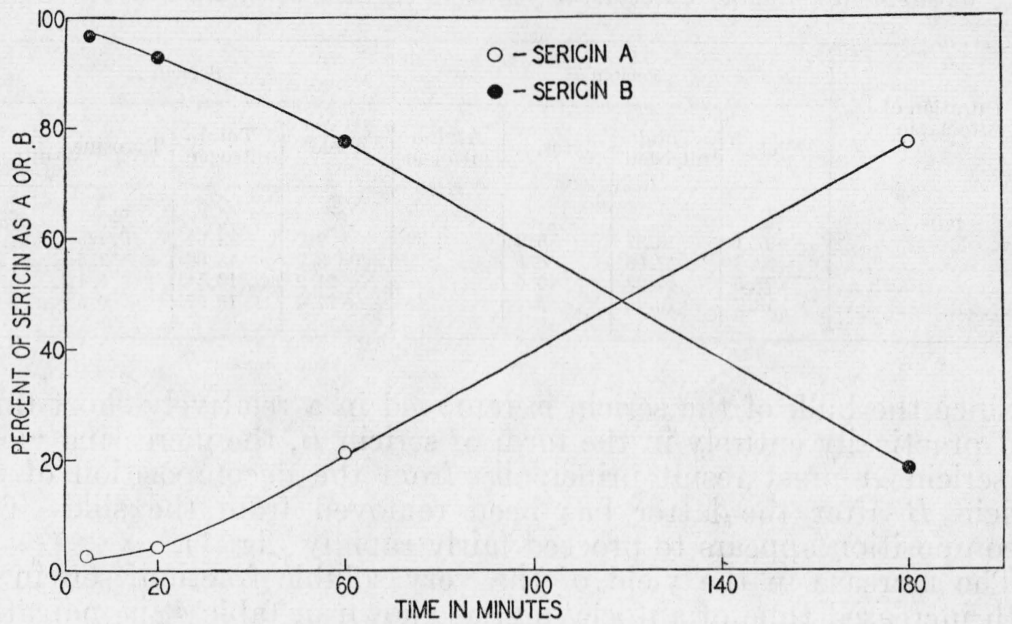

FIGURE 1.-Effect of duration of autoclaving on the yields of sericins $A$ and $B$.

TABLE 2.-Effect of duration of autoclaving on the yields of sericin $A, B$, and $D$

\begin{tabular}{|c|c|c|c|c|c|}
\hline Duration of autoclaving & $\begin{array}{l}\text { Loss in } \\
\text { weight of } \\
\text { dewaxed } \\
\text { silk }\end{array}$ & Sericin $B$ & Sericin $A$ & Sericin $D$ & $\begin{array}{l}\text { Total ex- } \\
\text { tracted } \\
\text { sericin ac- } \\
\text { counted for }\end{array}$ \\
\hline $\begin{array}{l}\quad \min \\
60 \\
180\end{array}$ & $\begin{array}{r}\text { \% } \\
12.6 \\
18.9 \\
21.1 \\
22.9\end{array}$ & $\begin{array}{r}\% \\
\text { \% } \\
97.1 \\
93.3 \\
77.5 \\
18.7\end{array}$ & $\begin{array}{r}\% \\
2.7 \\
3.7 \\
21.2 \\
77.4\end{array}$ & $\begin{array}{r}\text { \% } \\
\text { Trace } \\
1.1 \\
1.3 \\
3.8\end{array}$ & $\begin{array}{r}\% \\
99.8 \\
98.1 \\
100.0 \\
99.9\end{array}$ \\
\hline
\end{tabular}

The data clearly show that sericin $A$ is a decomposition product of the naturally occurring sericin, and is formed during the autoclave treatment. If, however, fraction $A$ were present in the native raw silk, it would be expected that it would be more rapidly removed, because of its high solubility. Actually, the sericin samples obtained in the shortest times of autoclaving (5 to 20 minutes) were practically entirely in the form of sericin $B$.

Further evidence supporting the conclusion that the fractions of sericin result from decomposition produced during autoclaving of the fibers is found in the analytical data of the different fractions, as shown in table 3. The data show that sericins $A$ and $B$ as obtained under these conditions are not definite chemical entities but are substances whose chemical compositions vary with the length of the autoclave treatment. A comparison of these data with the calculated total and amino nitrogen, and tyrosine contents of sericin in dewaxed silk (table 1) indicates that the sericin $B$ fraction, obtained from silk during autoclaving for only 5 minutes, is probably very similar to the undegraded 
sericin. This similarity and the fact that more than 97 percent of the sericin removed in this time is sericin $B$ strongly suggest that all of the sericin in raw silk is present in one form.

TABLE 3.-Nitrogen and tyrosine contents of the sericin fractions obtained from dewaxed silk during autoclaving for different lengths of time at $115^{\circ} \mathrm{C}$

\begin{tabular}{|c|c|c|c|c|c|c|c|c|}
\hline \multirow{2}{*}{$\begin{array}{l}\text { Duration of } \\
\text { autoclaving }\end{array}$} & \multicolumn{4}{|c|}{ Sericin $B$} & \multicolumn{4}{|c|}{ Sericin $A$} \\
\hline & Yield & $\begin{array}{c}\text { Total } \\
\text { nitrogen }\end{array}$ & Tyrosine & $\underset{\text { nitrogen }}{\text { Amino }}$ & Yield & $\begin{array}{c}\text { Total } \\
\text { nitrogen }\end{array}$ & Tyrosin $\theta$ & $\begin{array}{c}\text { Amino } \\
\text { nitrogen }\end{array}$ \\
\hline $\begin{array}{c}\text { min } \\
500 \\
600 \\
180\end{array}$ & $\begin{array}{l}\% \\
97.1 \\
93.3 \\
77.5 \\
18.7\end{array}$ & $\begin{array}{l}\% \\
16.87 \\
17.00 \\
17.23 \\
16.44\end{array}$ & $\begin{array}{l}\%_{6.2} \\
6.5 \\
6.5 \\
5.4\end{array}$ & $\begin{array}{c}\% \\
0.32 \\
.45\end{array}$ & $\begin{array}{r}\% \\
\% .7 \\
3.7 \\
21.2 \\
77.4\end{array}$ & $\begin{array}{l}\% \\
13.94 \\
15.68 \\
16.44 \\
16.67\end{array}$ & \begin{tabular}{r}
\multicolumn{1}{c}{$\%$} \\
Trace \\
2.5 \\
5.1 \\
6.5
\end{tabular} & $\begin{array}{c}\% \\
0.49 \\
\end{array}$ \\
\hline
\end{tabular}

Since the bulk of the sericin is removed in a relatively short time, and practically entirely in the form of sericin $B$, the increasing yields of sericin $A$ must result principally from the decomposition of the sericin $B$ after the latter has been removed from the silk. This decomposition appears to proceed fairly rapidly (fig. 1).

The increase in the yield of the very soluble fraction, sericin $D$, with increased time of autoclaving, as shown in table 4 , is indicative of even more extreme decomposition of the sericin. The chief interest in this fraction is found in its relatively high carbohydrate and amino-sugar contents. The samples obtained after 20 minutes contain about three times as much of these substances as the original sericin. It should be noted, however, that although there is a fourfold increase in yield of sericin $D$ when the duration of the autoclave treatment is extended from 20 to 180 minutes, there is only a comparatively small increase in the total yields of amino sugar and carbohydrate. In other words, the first of these very soluble decomposition products is relatively rich in these substances, but the subsequent fractions of the sericin contain appreciably lower amounts.

TABLE 4.-Effect of the duration of the autoclave treatment on the yield of sericin $D$

\begin{tabular}{|c|c|c|c|c|}
\hline Duration of autoclave treatment & $\begin{array}{l}\text { Yield } a \text { of } \\
\text { sericin } D\end{array}$ & $\begin{array}{l}\text { Carbohydrate } \\
\text { (as glucose) }\end{array}$ & $\begin{array}{c}\text { Amino suga } \\
\text { glucosami }\end{array}$ & ir (as \\
\hline $\min$ & \multirow{2}{*}{$\begin{array}{cc}m g & \\
& 102 \\
& 134 \\
& 432\end{array}$} & \multirow{2}{*}{$\begin{array}{rr}m g & 4.7 \\
6.4 \\
7.4\end{array}$} & \multirow[t]{2}{*}{$m g$} & \multirow{2}{*}{$\begin{array}{l}4.0 \\
6.1 \\
6.9\end{array}$} \\
\hline $\begin{array}{l}60 \\
180\end{array}$ & & & & \\
\hline
\end{tabular}

- Yield from $50 \mathrm{~g}$ of dewaxed silk.

The data in table 3 also show that the conversion of sericin $B$ to $A$ is accompanied by an increase in amino-nitrogen content, sufficient to account for an appreciable amount of hydrolysis. Additional evidence that hydrolytic decomposition occurs during treatment of sericin with boiling water was obtained in the following experiment. A sample of dewaxed silk was placed in boiling water and aliquots of the resulting sericin solution were removed at different time intervals 
for the determination of total and amino nitrogen. The results are presented in figure 2, and show that hydrolysis of the sericin proceeds at an appreciable and fairly constant rate.

No attempt has been made to isolate the sericin $C$ fraction because, as shown above, none of the isolated fractions has any particular significance as regards the sericin as it exists in the raw silk.

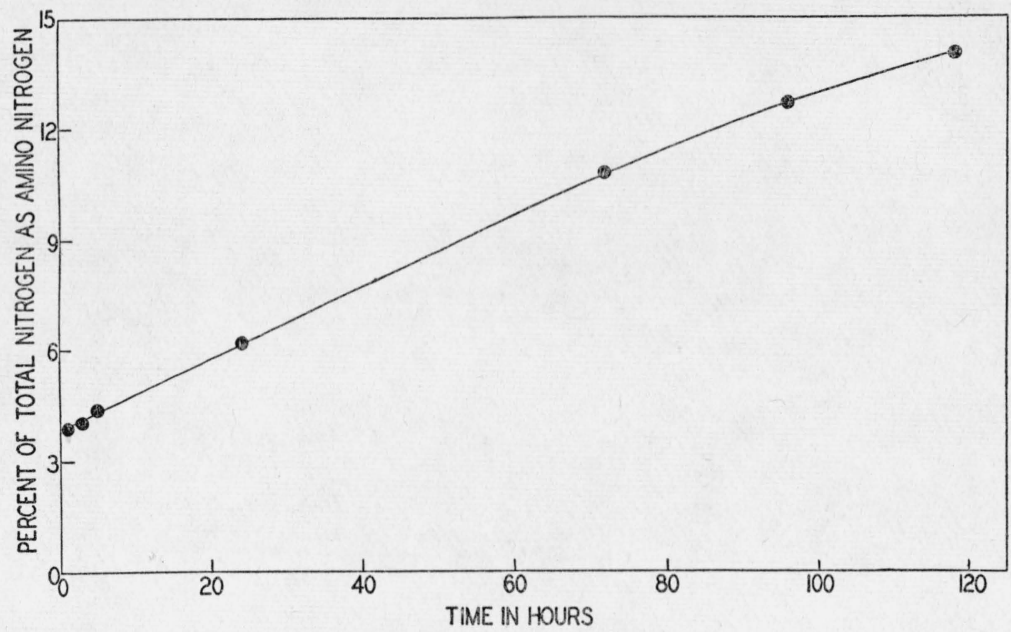

FIGURE 2.-Rate of increase of the amino-nitrogen content of a sericin solution during prolonged treatment at $100^{\circ} \mathrm{C}$.

\section{REFERENCES}

[1] La Dissolution du Vernis de Soie, Rigaut de Saint Quentin (1784).

[2] Cramer, J. prakt. Chem. 96, 76 (1865).

[3] Wetzel, Z. physiol. Chem. 26, 535 (1898).

[4] Bondi, Z physiol. Chem. 34, 481 (1901).

[5] Fischer and Skita, Z. physiol. Chem. 35, 221 (1902).

[6] Anderlini, Chem. Zentr. [II] 1887 941; [I] 1898795.

[7] Shelton and Johnson, J. Am. Chem. Soc. 4\%, 412 (1925).

[8] Mosher, Am. Dyestuff Reptr. 21, 341 (1932); Am. Silk and Rayon J. 53, 43 (1934).

[9] Kaneko, J. Agr. Chem. Soc. Japan 9, 45 (1933).

[10] Ito and Komori, Bul. Agr. Chem. Soc. Japan 13, 115 (1937); 15, 50 (1939).

[11] Lugg, Biochem. J. 31, 1422 (1937); 32, 775 (1938).

[12] Rutherford, Harris, and Smith, J. Research NBS 19, 467 (1937) RP1038.

[13] Van Slyke, J. Biol. Chem. 9, 185 (1911); 12, 275 (1912).

[14] Sørensen and Haugaard, Compt. rend. trav. lab. Carisberg. Sér. chim. 19, 1 (1933).

[15] Sørensen, Compt. rend. trav. lab. Carlsberg. Sér. chim. 22, 487 (1938).

Washington, January 27, 1940. 